\title{
VARIABILIDADE ESPACIAL DE ATRIBUTOS FÍSICOS DO SOLO EM UMA SUB-BACIA ÀS MARGENS DO RIO MOGI GUAÇU (SP)
}

\author{
SPATIAL VARIABILITY OF SOIL PHYSICAL ATTRIBUTES ON THE BANKS OF THE \\ MOGI GUAÇU RIVER, SÃO PAULO
}

\section{Gustavo Klinke NETO ${ }^{1}$, Anna Hoffmann OLIVEIRA ${ }^{2}$, Sueli Yoshinaga PEREIRA ${ }^{3}$}

(1) Programa de Pós-Graduação em Geociências, Instituto de Geociências, Universidade Estadual de Campinas - Rua João Pandiá Calógeras, 51, Cidade Universitária - Barão Geraldo, CEP: 13083-870, Campinas - São Paulo. Endereço eletrônico: guklinke@ige.unicamp.br

(2) Instituto de Geociências, Universidade Estadual de Campinas -Rua João Pandiá Calógeras, 51, Cidade Universitária - Barão Geraldo, CEP: 13083-870, Campinas - São Paulo. Endereço eletrônico: annahoffmann@ige.unicamp.br

(3) Instituto de Geociências, Universidade Estadual de Campinas -Rua João Pandiá Calógeras, 51, Cidade Universitária - Barão Geraldo, CEP: 13083-870, Campinas - São Paulo. Endereço eletrônico: sueliyos@ige.unicamp.br

\author{
Introdução \\ Material e Métodos \\ Resultados e Discussão \\ Conclusões \\ Agradecimentos \\ Referências
}

\begin{abstract}
RESUMO - A espacialização dos atributos do solo é de grande importância na interpretação geográfica da paisagem especialmente quando o foco desejado são as questões hidrogeológicas acerca da capacidade de infiltração da água no solo, sendo a condutividade hidráulica seu indicador direto. Assim, este trabalho buscou verificar a existência de dependência espacial para as variáveis areia, argila, silte, densidade, micro e macro porosidade, volume total de poros e condutividade hidráulica, bem como analisar sua variabilidade e sua espacialização através da Krigagem Ordinária. O estudo foi conduzido em área de planície aluvial, adjacente ao Rio Mogi Guaçu. Os resultados encontrados confirmaram a relação de dependência espacial de todos os atributos analisados na escala pesquisada e revelaram a anisotropia dos atributos condutividade hidráulica, macroporosidade e volume total de poros. Todos os atributos obtiveram seus melhores ajustes no modelo esférico. A relação direta entre macroprorosidade e condutividade hidráulica também foi verificada nas amostras coletadas, colocando a macroporosidade como um bom indicador da capacidade de infiltração em campo.
\end{abstract}

Palavras-chave: Propriedades Hidrodinâmicas do Solo, Geoestatística, Krigagem, Espacialização.

\begin{abstract}
The spatial distribution of soil properties is very important in geographical landscape interpretation especially when the desired focus are the hydro-geological questions about the water infiltration capacity of the soil, being the hydraulic conductivity your direct indicator. So this study aimed to verify the existence of spatial dependence for the variables, sand, clay, silt, density, micro and macroporosity, total pore volume and hydraulic conductivity, as well as analyze its variability and its spatial distribution by Ordinary Kriging. The study was conducted in area of alluvial plain, adjacent to the river Mogi Guaçu. The results confirmed the relationship of spatial dependency for all attributes analyzed in the research scale and revealed the anisotropy of the attributes hydraulic conductivity, macro porosity and total pore volume. All attributes obtained their best fitting in spherical model. The direct relationship between macro porosity and hydraulic conductivity was also found in the field samples, placing macro porosity as a good field indicator around the infiltration capacity.
\end{abstract}

Keywords: Hydrodynamic Properties ofSsoil, Geostatistic, Kriging, Spatial Variability.

\section{INTRODUÇÃO}

Depósitos aluviais são componentes singulares do registro geológico que apresentam destacada importância ao permitirem a caracterização dos processos hidrodinâmicos, como no caso das águas subterrâneas, e a compreensão da evolução sedimentar dos depósitos antigos de uma bacia (Teixeira et al., 2003). A planície aluvionar do Rio Mogi Guaçu está inserida na mais importante província hidrogeológica do Brasil, a Bacia do Paraná, a qual compreende aproximadamente 45\% das reservas de água subterrânea do país. A acumulação de grande espessura de rochas sedimentares é característica deste sistema de drenagem (IPT, 1981), que abrange os Estados do Paraná, Santa Catarina,
Rio Grande do Sul, Mato Grosso, Mato Grosso do Sul, Goiás, sul de Minas Gerais e quase toda a porção interiorana do Estado de São Paulo (Petri \& Fúlfaro, 1983), particularmente nos domínios de Mogi Mirim e Mogi Guaçu, local da presente pesquisa, onde tais rochas possuem boa espessura e normalmente estão associadas a ocorrência de águas subterrâneas sem confinamento pertencentes ao Aquífero Itararé (Chang et al., 2012).

Em depósitos sedimentares muito recentes, tal como o material aluvial depositado às margens dos rios, lagos e encostas íngremes muito erodidas, ocorrem solos muito influenciados pelo material de origem e 
caracteristicamente muito variáveis a pequenas distâncias, tanto na horizontal quanto na vertical. Tal variação requer maiores esforços de amostragem em campo a fim de determinar o comportamento dos atributos de interesse. Nestas condições, há uma demanda técnicocientífica no sentido de se prever valores em locais não amostrados a qual a metodologia geoestatística procura suprir. A partir de uma aparente aleatoriedade dos dados coletados, a geoestatística busca extrair uma função de correlação entre os valores situados numa determinada vizinhança e direção no espaço amostrado (Landim \& Sturaro, 2002). Uma vez encontrada esta correlação espacial, o método interpolador para as estimativas dos valores entre as amostras é o da krigagem. A Krigagem Ordinária (K.O.) é popular em estudos em todo o mundo sendo utilizada inicialmente por pedólogos, hidrólogos, geólogos e pesquisadores da atmosfera e atualmente atinge áreas como engenharia do petróleo, mineração, meteorologia, ciências do solo, agricultura de precisão, controle de poluição, saúde pública, pesca, ecologia vegetal e animal e sensoriamento remoto (Oliver \& Webster, 2014).

Assim como outras variáveis ambientais, os atributos do solo são pesquisados através de amostras e que, na realidade, representam um espaço contínuo no qual as amostras foram retiradas. A grande popularidade da krigagem vem do fato de que suas estimativas nos pontos não amostrados são confiáveis, ou seja, sem parcialidade e com variância mínima, bem como sem erros de excessos (Oliver \& Webster, 2014). Segundo Silva et al. (2015), no que se refere à interpolação de atributos do solo, a K.O. é o método mais utilizado.

A variação dos atributos do solo é descrita em muitos estudos de estatística clássica como uma função aleatória, contudo, também é reconhecido que as variações espaciais dos solos têm, como fonte primária, os fatores pedogenéticos e, como fonte secundária, o uso e manejo do solo. Em muitos casos, a variação espacial tende a diminuir com a distância entre os pontos amostrados (Cerri et al., 2004).

No caso da avaliação das propriedades hidrodinâmicas do solo, variáveis espacialmente em função do relevo e conforme a estruturação do solo, considerando seus componentes sólidos (textura, agregação e horizontes) e o espaço poroso, é possível inferir sobre a recarga dos aquíferos. Ademais, potenciais indicadores hidrológicos do solo não estão restritos somente aos primeiros centímetros do solo haja vista o deslocamento da frente de molhamento, o que os caracteriza como eficazes na avaliação da recarga de água subterrânea. Este fato foi constatado por Alvarenga et al. (2012), ao avaliarem a recarga de água subterrânea a partir da análise conjunta da textura, macroporosidade e densidade do solo, além da condutividade hidráulica, que reflete as condições de permeabilidade do meio.

A recarga tem início com a infiltração da água superficial e através do perfil do solo, alcançando os aquíferos. Este processo pode levar dias, meses ou anos dependendo das características dos aquíferos, tais como sua profundidade, geologia e transmissividade. Contudo, em função das características pedogenéticas, pode ocorrer uma importante concentração de subsuperfície, cujo fluxo de água também pode contribuir para a zona saturada, o fluxo no canal e a recarga em profundidade (Mello \& Curi, 2012). Dessa forma, sob condições específicas, a área pode apresentar a predominância de certos fluxos preferenciais e, consequentemente, ter o ciclo hidrológico afetado pelo próprio comportamento do solo (Menezes et al., 2009; Alvarenga et al., 2011).

Tendo em vista estas considerações, a espacialização dos atributos do solo ganha grande importância na interpretação geográfica da paisagem, especialmente quando o foco desejado são as questões hidrogeológicas acerca da capacidade de infiltração da água no solo. Atributos como textura, densidade e condutividade, somados à topografia da paisagem, constituem nos principais fatores que interferem diretamente na taxa de infiltração da água no solo e na capacidade de retenção de água sobre a superfície. Portanto, sob a perspectiva da redistribuição da água na paisagem, a capacidade de infiltração do solo destaca-se por ser um processo que atua como integrador das características intrínsecas do solo.

Neste contexto, o presente estudo pretende analisar e descrever a variabilidade dos atributos físico-hídricos do solo, bem como especializá-los, a fim de gerar subsídios para abordagem do potencial de infiltração de água 
no solo para recarga de águas subterrâneas em área de planície aluvial, adjacente ao Rio Mogi Guaçu. Além disso, como objetivos secundários pretende-se verificar a existência de depen- dência espacial e anisotropia nos atributos analisados, bem como analisar a relação destes atributos com a capacidade da infiltração do solo através da condutividade hidráulica.

\section{MATERIAL E MÉTODOS}

A área de estudo está inserida às margens do Rio Mogi Guaçu, no município de Mogi Guaçu, SP, mais precisamente no Complexo de Unidades de Conservação de Mogi Guaçu (CUCMG) composto pela Estação Ecológica (EEc), Estação Experimental (EEx) e Instituto

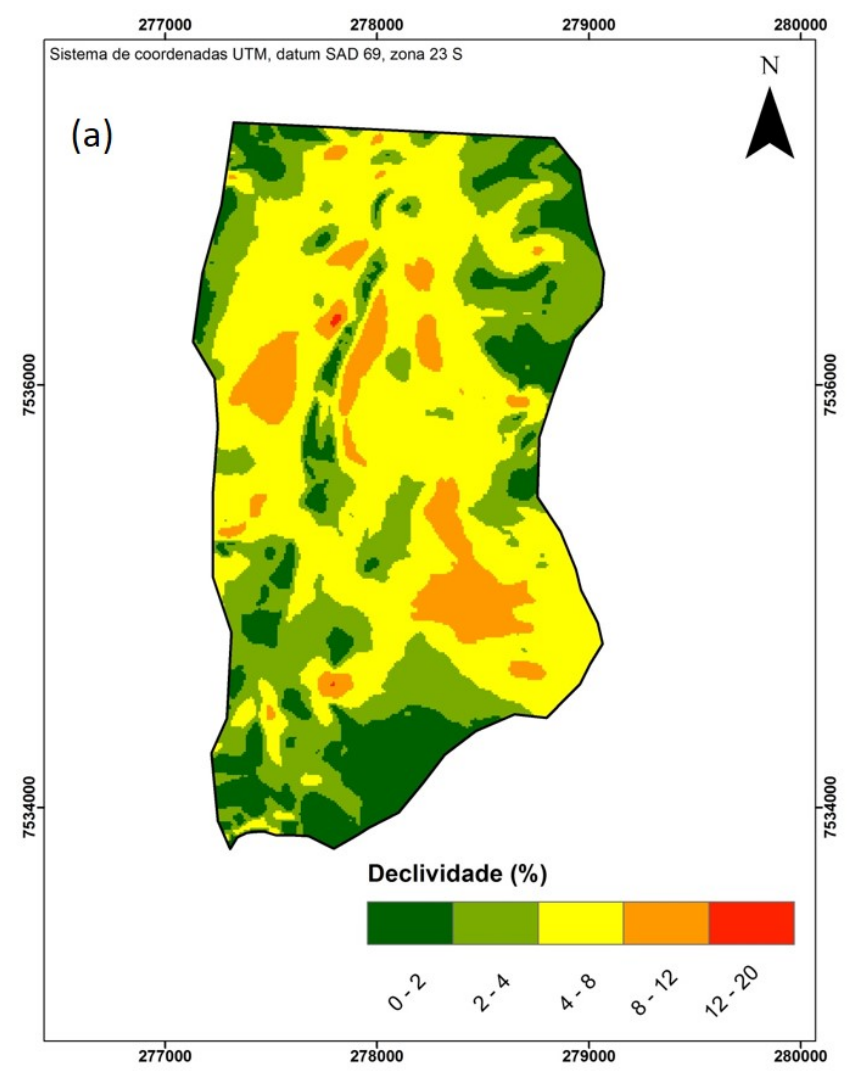

de Botânica (IB).

Localizada dentro da EEc a área possui aproximadamente $5 \mathrm{~km}^{2}$, um perímetro de cerca de $10 \mathrm{~km}$ e predominância de relevo suave ondulado, com declividade média de 5\% (Figura 1a).

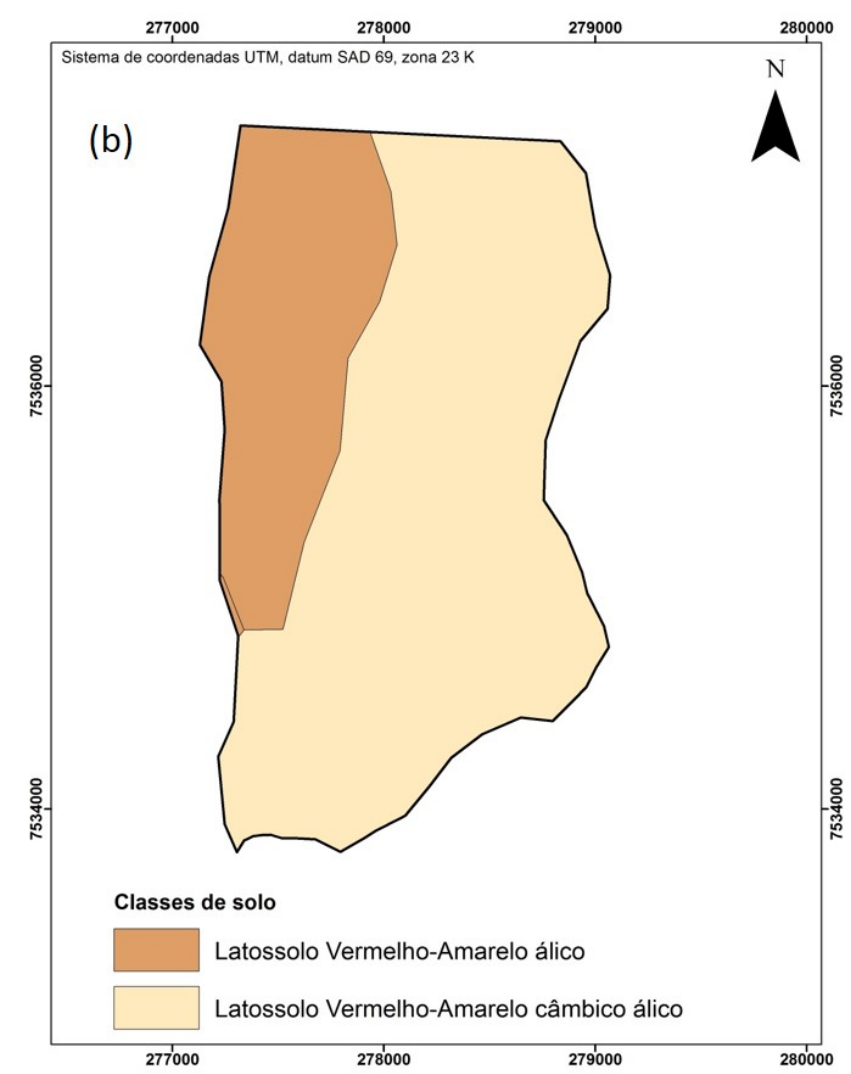

Figura 1 - Mapas de declive (a) e de classes de solo (b) da sub-bacia de estudo. Sistema de coordenadas UTM, datum SAD 69, zona 23S(K).

A classe de solo predominante é o Latossolo Vermelho-Amarelo (LVA) (Figura 1b), sendo que o LVA cambissólico álico ocupa a maior parte da área, cerca de 75\%, e localiza-se preferencialmente nos terraços; e o LVA álico nas demais porções correspondentes às áreas mais baixas. Nesta área, os solos são formados a partir de rochas areníticas da Formação Aquidauana e de Depósitos Aluvionares (Embrapa, 2006).

Os principais usos do solo na área são: florestas plantadas de Pinus e Eucalipto, floresta nativa representada pela Floresta Estacional Semidecidual Aluvial (FESDA) e pastagem (Figura 2). O clima definido para a área varia, de acordo com a classificação de Koppen, entre clima Aw (clima tropical com estação seca de inverno e chuvosa no verão) e clima Cwa (clima temperado úmido com inverno seco e verão quente). $\mathrm{Na}$ Bacia Hidrográfica do Rio Mogi Guaçu as temperaturas médias anuais variam de $20,5{ }^{\circ} \mathrm{C}$ a $22,5{ }^{\circ} \mathrm{C}$ e as precipitações médias anuais variam de 1.400 a $1.600 \mathrm{~mm}$ (Sparovek et al., 2007).

Para o estudo da variabilidade espacial foi delineada uma malha amostral regular de $400 \mathrm{x}$ 400 metros em toda a área, totalizando 34 
pontos de coleta. Em cada ponto foram coletadas amostras de solo deformadas e indeformadas segundo Santos et al. (2005), na camada de 20 a $40 \mathrm{~cm}$, para as seguintes análises: areia (\%), argila (\%), silte (\%) (Bouyoucos ,1951), densidade do solo (Ds) $\left(\mathrm{g} / \mathrm{cm}^{3}\right)$ (Blake, 1965), macroporos (Ma) (\%), microporos (Mi) (\%) (Grohmann, 1960), volume total de poros (Vtp) (\%) (Danielson \& Sutherland, 1986) e condutividade hidráulica saturada (K0) (cm/h) (Klute, 1965). As amostras com estrutura indeformada foram coletadas com o amostrador de Uhland e submetidas às seguintes análises: Ds, Ma, Mi, Vtp e K0.

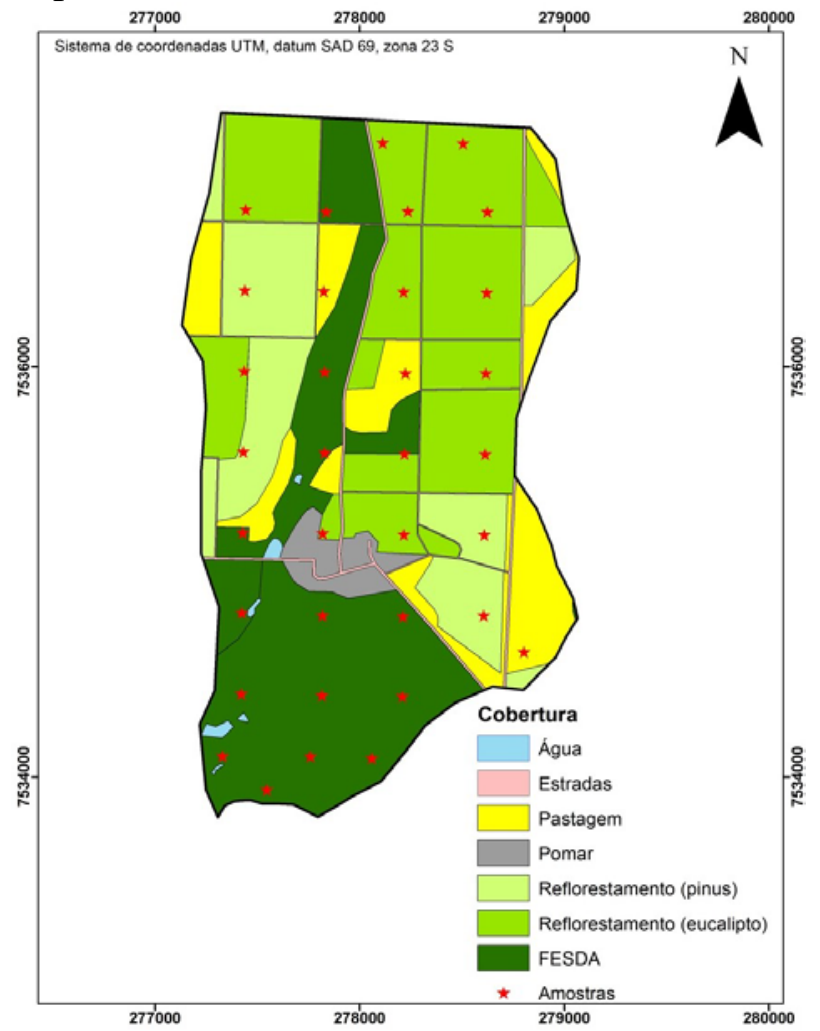

Figura 2 - Mapa de uso e ocupação do solo da sub-bacia de estudo. Sistema de coordenadas UTM, datum SAD 69, zona $23 S(\mathrm{~K})$.

Constituindo informação à parte das análises estatísticas, foi realizado o fracionamento da areia com o intuito de complementar as informações levantadas.

Em vista da preparação dos dados para a análise geoestatística, foi realizada uma análise estatística descritiva dos dados onde, para cada variável estudada, os seguintes parâmetros foram avaliados: máximo, mínimo, amplitude, média, variância e coeficiente de variação (CV).

Também foram calculadas as correlações entre todas as variáveis estudadas de acordo com o coeficiente de Pearson apresentado a seguir:

$$
\rho=\frac{\sum_{i=1}^{n}\left(x_{i}-\bar{x}\right)\left(y_{i}-\bar{y}\right)}{\sqrt{\sum_{i=1}^{n}\left(x_{i}-\bar{x}\right)^{2}} \times \sqrt{\sum_{i=1}^{n}\left(y_{i}-\bar{y}\right)^{2}}}
$$

onde: $x$ e $y$ são os valores medidos de ambas as variáveis em teste.

O gráfico de dispersões dos desvios em relação a média foi elaborado e permitiu a identificação e exclusão de quatro amostras que ficaram fora da distribuição esperada, com valores discrepantes, excessivamente altos ou baixos frente o conjunto de dados. Este procedimento é de grande importância, pois tais valores afetam muito o desempenho dos modelos geoestatísticos causando distorções irreais (Oliver \& Webster, 2014). Por fim, 30 amostras permaneceram para a modelagem espacial, três das quais foram aleatoriamente selecionadas para a validação externa do modelo e, portanto, não utilizadas na construção dos variogramas.

O variograma descreve a relação entre a variabilidade das amostras em vista das distâncias e/ou direções existentes entre elas, buscando-se por fim uma relação descrita como dependência espacial, que conecta o aumento da variabilidade com o aumento da distância entre elas. Segundo Landim \& Sturaro (2002) o variograma representa o comportamento espacial de uma variável regionalizada ou de seus resíduos, podendo indicar anisotropias, descontinuidades e zonas de influência da variável analisada. Diversas pesquisas veem demostrando uma clara dependência espacial dos atributos do solo principalmente em levantamentos detalhados ou em áreas onde os limites entre as classes de solo não são claros (Oliver \& Webster, 2014).

Matematicamente o variograma é definido pela equação a seguir:

$$
\gamma(h)=\frac{1}{2 m(h)} \sum_{j=1}^{m(h)}\left\{z\left(x_{j}\right)-z\left(x_{j}+h\right)\right\}^{2}
$$

onde $\mathrm{m}(\mathrm{h})$ é o número de comparações pareadas no intervalo (passo) h.

Foram construídos, para cada atributo, variogramas em 4 direções distintas 45 graus entre si (azimutes $0^{\circ}, 45^{\circ}, 90^{\circ}$ e $135^{\circ}$ ) para verificação de possíveis anisotropias nos dados. 
A aplicação da metodologia geoestatística seguiu os procedimentos clássicos descritos por Matheron (1965) e as considerações de Oliver \& Webster (2014) sendo testados os modelos teóricos esférico, exponencial e gaussiano apresentados a seguir:

- Modelo esférico:

$$
\begin{aligned}
& \gamma(h)=C_{0}+C_{1}\left[\frac{3}{2}\left(\frac{h}{a}\right)-\frac{1}{2}\left(\frac{h}{a}\right)^{3}\right] \quad 0<h<a \\
& \gamma(h)=c_{0}+C_{1} \quad h \geq a \\
& \gamma(h)=C_{0}+C_{1}\left[1-\exp \left(-3 \frac{h}{a}\right)\right] 0<h<a
\end{aligned}
$$

onde: $C_{0}=$ Efeito pepita; $C_{0}+C_{1}=$ Patamar; $a=$ alcance.

O ajuste de cada modelo testado foi feito levando-se em consideração o conceito de continuidade existente nos atributos do solo, a variância das amostras, a conformidade visual do ajuste e também o cálculo da soma dos quadrados dos resíduos (acrónimo em inglês RSS). Segundo Oliver \& Webster (2014) diversas pesquisas podem ser encontradas com ajustes visuais dos modelos, o que pode acarretar em estimativas irreais e tendenciosas. O indicado é associar o ajuste visual ao uso de indicadores matemáticos sendo o mais indicado a soma dos quadrados dos resíduos (RSS) (Chilès \& Delfiner, 2012). A RSS produz uma medida exata da capacidade de ajuste do modelo aos dados de origem. Quanto menor o RSS, melhor o ajuste do modelo (Robinson \& Metternicht, 2006). A RSS é dada pela fórmula:

$$
R S S=\sum_{i=1}^{n}\left[y_{i}-f\left(x_{1}\right)\right]^{2}
$$

onde: $y=$ valor etimado; $f\left(x_{1}\right)=$ valor real.

Para a confirmação da anisotropia em alguns atributos, foi verificado no modelo escolhido se haviam ou não diferenças significativas entre o alcance maior (na suposta direção da anisotropia) e o alcance menor (direção de menor continuidade). Caso o modelo ajustado apresentasse alcances iguais ou muito similares em ambas as direções o atributo era considerado isotrópico, caso os alcances fossem diferentes, o atributo era considerado anisotrópico. Os atributos considerados isotrópicos tiveram seus variogramas refeitos de maneira ominidirecional e, assim, foram ajustados e selecionados como descrito anteriormente.

Os mapas espacializados das variáveis foram gerados a partir da Krigagem Ordinária (K.O.), considerando os melhores modelos teóricos ajustados para cada atributo. Os mapas krigados foram testados pela validação externa, que compara valores conhecidos (amostras) com valores estimados (K.O.), através do teste de Tukey a 5\% de significância.

\section{RESULTADOS E DISCUSSÃO}

Os resultados da análise descritiva dos atributos do solo para os valores de argila, silte, areia, Ds, Ma, Mi, Vtp e K0 são apresentados na Tabela 1. De acordo com a classificação de coeficiente de variação (CV) proposta por Warrick \& Nielsen (1980), os atributos areia,

Tabela 1 - Estatística descritiva dos atributos amostrados.

\begin{tabular}{l|c|c|c|c|c|c}
\hline Atributos & Máximo & Mínimo & Amplitude & Média & Variância & CV (\%) \\
\hline Areia (\%) & 87,2 & 65,32 & 21,88 & 77,41 & 38,50 & 8,02 \\
\hline Argila (\%) & 25,46 & 9,93 & 15,53 & 16,65 & 23,01 & 28,81 \\
\hline Silte (\%) & 23,22 & 2,13 & 21,09 & 5,94 & 16,13 & 67,58 \\
\hline Ds (g/cm) & 1,8 & 1,41 & 0,39 & 1,60 & 0,01 & 6,74 \\
\hline Ma (\%) & 25,18 & 3,05 & 22,13 & 13,45 & 28,92 & 39,98 \\
\hline Mi (\%) & 30,03 & 13,49 & 16,54 & 23,41 & 17,97 & 18,11 \\
\hline Vtp (\%) & 42,63 & 24,72 & 17,91 & 36,86 & 16,47 & 11,01 \\
\hline K0 (cm/h) & 41,61 & 0,06 & 41,55 & 7,31 & 82,33 & 124,14 \\
\hline
\end{tabular}

Legenda- CV: coeficiente de variação; Ds: densidade do solo; K0: condutividade hidráulica saturada; Ma: macroporosidade; Mi: microporosidade; Vtp: volume total de poros. 
Ds e Vtp apresentaram CV baixo ( $<12 \%)$, indicando uma maior homogeneidade, já argila, Ma e Mi apresentaram CV médio (12 a 60\%). Os atributos $\mathrm{K} 0$ e silte apresentaram alta variabilidade (> 60\%), sendo 67 e $124 \%$ (Tabela 1), respectivamente, representando materiais bastante heterogêneos.

As análises granulométricas revelaram que os solos da área de estudo possuem textura média a arenosa, com percentuais de areia variando de 65 a 87 (Tabela 1), o que confere com o material de origem referente às rochas areníticas da Formação Aquidauana, unidade litoestratigráfica pertencente à Bacia Sedimentar do Paraná do Rio Mogi Guaçu.

O fracionamento da areia apontou uma média de $8 \%$ para areia muito grossa, $15 \%$ para areia grossa, 35\% para areia média, 33\% de areia fina e $4 \%$ de areia muito fina. As partículas de menor tamanho como argila e, principalmente, silte, foram encontradas em quantidades relativamente pequenas, sendo $16 \%$ a média de argila e $6 \%$ a média de silte.

A textura do solo é um atributo fundamental ao entendimento do comportamento físico-hídrico do solo, pois afeta de forma marcante a capacidade de infiltração. Verificou-se que os solos na área estudada apresentam condições favoráveis ao fluxo de água e drenagem do solo, o que confere elevado potencial de recarga de água subterrânea no que se refere à classe textural. As pequenas quantidades de silte associadas a grandes porções arenosas garantem uma boa permeabilidade aos solos estudados, uma vez que em áreas com muito silte a possibilidade de obstrução dos poros é potencializada, diminuindo significativamente a permeabilidade do solo (Santos et al., 2012a). Os mesmos resultados também foram observados por Batista \& Couto (1992) ao avaliar a textura do solo na Reserva Biológica de Mogi Guaçu, os quais ressaltaram os baixos teores de silte característicos do Latossolo Vermelho-Amarelo textura média e a pequena variação porcentual na composição granulométrica. O silte apresentou CV maior do que as frações areia e argila (Tabela 1), fato que pode estar relacionado a grande mobilidade destas partículas no solo bem como a grande movimentação de massa nas planícies aluviais (Santos et al., 2012b).
A porosidade define a relação entre 0 volume de poros e o volume total de solo, sofrendo influência tanto da textura como da estrutura do solo. O Vtp variou de $32,5 \%$ a 46,9\%, com uma média de 38,9\% (Tabela 1). Determinante na formação da porosidade, a textura explica a ocorrência de poros grandes em solos arenosos, os quais também apresentam baixa porosidade total comparado a solos mais argilosos devido ao maior volume de microporos nestes últimos. De acordo com Freire (2006), uma porosidade de $50 \%$ é esperada para solos de textura franca e de 40 a 60\% para solos arenosos. Assim, pode-se inferir que o Vtp se apresenta abaixo do esperado em alguns pontos, mas em termos médios está próximo ao intervalo esperado. Atualmente, como não há manejo e interferência antrópica, é possível ponderar que a elevada densidade vegetal na área com o consequente crescimento das raízes favorece a atividade biológica e a abertura de poros no solo, mantendo a sua estrutura preservada.

A distribuição dos poros na matriz do solo determina a evolução espacial e temporal dos processos que envolvem o movimento da água no solo, de forma que a distribuição dos poros por tamanho condiciona o comportamento físico-hídrico do solo. O volume de Ma é determinante na dinâmica de água no solo e variou de 3 a 25\% com média de $14 \%$ (Tabela 1), resultados muito similares aos observados por Carvalho et al. (2003), cujos valores de macroporosidade variaram de 3 a 29\% com média de 14\% para Argissolos e Latossolos. Ribeiro et al. (2007) relatou uma menor média de $\mathrm{Ma}$, de $12 \%$, em LVA. A Ma média observada na área de estudo é considerada adequada para a aeração e desenvolvimento das plantas, conforme Baver et al. (1972), que estabelece um mínimo de $10 \%$ como condição ideal.

O volume de $\mathrm{Mi}$ alcançou 65\%, com mínimo de 13\% e média de 25\% (Tabela 1). Em solos arenosos, os maiores valores de microporosidade podem ser explicados pela constituição da fração areia, composta predominantemente por areia média e fina. Este tamanho favorece o arranjo da partícula na massa de solo, que ocupa os espaços formados pelas partículas maiores de areia e, consequentemente, reduzem o volume de Ma 
em favorecimento do volume de Mi. Em termos médios, Ribeiro et al. (2007) constatou a mesma predominância de $\mathrm{Mi}$ atribuída a granulometria da areia e relatou a deficiência deste atributo em explicar o comportamento hidráulico nos solos Latossolo Vermelho (LV) e LVA, uma vez que obtiveram valores muito semelhantes para Mi que não foram correspondidos em K0 e Vtp.

A densidade do solo (Ds) sofre influência da textura, estrutura e do grau de compactação, fornecendo a medida da relação existente entre a massa de uma amostra de solo seca e a soma dos volumes ocupados pelas partículas e pelos poros (volume total). A Ds encontrada foi de 1,4 a $1,8 \mathrm{~g} \mathrm{~cm}^{-3}$ e CV de $7 \%$ (Tabela 1), classificada como de baixa variabilidade, concordando com os resultados de Carvalho et al. (2003) e Santos et al. (2012b) que encontraram CV abaixo de $10 \%$ para este atributo. Para solos arenosos a Ds varia de 1,3 a 1,8 $\mathrm{g} \mathrm{cm}^{-3}$, o que corrobora as análises granulométricas apresentadas anteriormente. Por ser um atributo dependente de manifestações que influenciam a disposição das partículas do solo, a Ds é capaz de fornecer indicações sobre a sua influência em propriedades como infiltração e retenção de água, permitindo analisar o estado de conservação do solo. Os valores de Ds verificados no presente trabalho estão associados à estrutura mais preservada do solo. Devido à ausência de atuação antrópica na área, a porosidade original do solo e a sua capacidade de transmitir água ao longo do perfil foram mantidas.

Tais observações são confirmadas a partir dos resultados de $\mathrm{K} 0$, a qual variou de baixa $\left(0,06 \mathrm{~cm} \mathrm{~h}^{-1}\right)$ a excessiva $\left(41,6 \mathrm{~cm} \mathrm{~h}^{-1}\right)$, com média de $7,3 \mathrm{~cm} \mathrm{~h}^{-1}$ (Tabela 1 ) classificada como de alta permeabilidade, segundo Kutílek \& Nielsen (1994). Os elevados valores podem ser explicados em função dos altos teores de areia, além de elevadas taxas de porosidade total e de macroporosidade. Resultado semelhante ao maior valor de K0 foi encontrado para Neossolo Quartzarênico sob mata nativa em estudo desenvolvido por Ribeiro et al. (2007), que também observaram alta permeabilidade média para
LVA distrófico sob mata nativa. Em relação à variabilidade, sob condições semelhantes as deste estudo Santos et al. (2012b) também encontraram CV alto, de $261 \%$, para K0. Os autores ressaltam que tal resultado é esperado devido à condição local, cujas deposições sucessivas de material com textura variável acarretaram em maior diversidade da condutividade hidráulica na planície aluvial onde se desenvolveu a pesquisa.

$\mathrm{Na}$ análise de correlação entre todos os atributos estudados e a K0, a macroporosidade foi a melhor, sendo de 0,53 e confirmando a relação direta entre esses atributos, uma vez que os macroporos são responsáveis por grande parte do transporte de água no perfil do solo (Santos et al., 2012b). A correlação encontrada foi muito similar à descrita para um Latossolo Vermelho-Amarelo distrófico em estudo conduzido por Amorim et al. (2011), com correlação de 0,47 entre a condutividade e a porosidade. A quantidade de macroporos apresentou ainda boa correlação com a quantidade de microporos e o Vtp. A relação direta encontrada entre a condutividade hidráulica e os poros do solo é descrita, entre outros, nos trabalhos de Furtunato et al. (2013) e Scherpinski et al. (2010), que também destacam o caráter essencialmente variável da porosidade não apenas entre diferentes solos, mas dentro de um mesmo solo em função das variações estruturais.

Para a abordagem geoestatística, inicialmente procedeu-se os ajustes dos três modelos teóricos testados (esférico, exponencial e gaussiano) em quatro direções. O melhor ajuste foi determinado em função do menor RSS encontrado. Assim, constatou-se que as pequenas anisotropias detectadas inicialmente nos variogramas de campo, não se refletiram necessariamente nos ajustes dos modelos teóricos, que em muitos casos resultaram em alcances e patamares idênticos nas quatro direções modeladas. Dessa forma, os atributos areia, silte, argila, densidade e microporosidade não apresentaram anisotropia no ajuste de seus modelos, sendo então considerados como isotrópicos e seus variogramas ajustados de forma omnidirecional, conforme apresentado na Tabela 2. Já os atributos macroporosidade, volume total de 
poros e a condutividade hidráulica confirmaram suas anisotropias também no ajuste dos modelos teóricos, que foram refletidas em diferentes alcances dependendo da direção de análise. Os resultados dos ajustes para as três variáveis anisotrópicas são apresentados na Tabela 3.

Durante os ajustes, foram feitos testes com acréscimos do efeito pepita e nenhum apresentou resultado mais satisfatório daqueles aqui apresentados. Todos os patamares ajustados foram muito próximos às suas respectivas variâncias e confirmaram a hipótese da estacionariedade na variância a partir de um certo alcance. A utilização do RSS como critério de qualidade no decorrer dos ajustes foi decisiva para o não estabelecimento de maneira equivocada do efeito pepita (Oliver \& Webster, 2014), uma vez que a bacia de estudo é coberta praticamente em sua totalidade por usos florestais refletindo, assim, a continuidade dos fatores pedogenéticos que neste caso se sobressaem.

Todos os atributos analisados, areia, silte, argila, Ds, Ma, Mi, Vtp e K0 e obtiveram seus melhores ajustes no modelo esférico. Este modelo é citado por Furtunato et al. (2013) como o mais frequentemente encontrado na ciência do solo.

Tabela 2 - Parâmetros de ajuste dos modelos isotrópicos testados.

\begin{tabular}{l|l|l|l|l|l}
\hline Variável & Modelo & Co & Co + C & Alcance & RSS \\
\hline Areia (\%) & Esférico & $\underline{0,1}$ & $\underline{40,35}$ & $\underline{939}$ & $\underline{28}$ \\
\hline Areia (\%) & Exponencial & 0,1 & 42,39 & 427 & 97,3 \\
\hline Areia (\%) & Gaussiano & 0,1 & 40,64 & 443 & 45 \\
\hline Argila (\%) & Esférico & $\underline{0,01}$ & $\underline{22,34}$ & $\underline{538}$ & $\underline{42,2}$ \\
\hline Argila (\%) & Exponencial & 1,11 & 22,32 & 170 & 49,1 \\
\hline Argila (\%) & Gaussiano & 2,24 & 22,41 & 266 & 43,9 \\
\hline Silte (\%) & Esférico & $\underline{0,01}$ & $\underline{16,27}$ & $\underline{829}$ & $\underline{21}$ \\
\hline Silte (\%) & Exponencial & 0,01 & 16,39 & 332 & 34,6 \\
\hline Silte (\%) & Gaussiano & 0,01 & 16,33 & 417 & 22 \\
\hline Ds (g/cm) & Esférico & $\underline{0,00061}$ & $\underline{0,01222}$ & $\underline{538}$ & $\underline{0,0000174}$ \\
\hline Ds (g/cm) & Exponencial & 0,00135 & 0,0121 & 137 & 0,00001829 \\
\hline Ds (g/cm) & Gaussiano & 0,0018 & 0,0122 & 259 & 0,00001757 \\
\hline Mi (\%) & Esférico & $\underline{0,01}$ & $\underline{18,66}$ & $\underline{556}$ & $\underline{33,9}$ \\
\hline Mi (\%) & Exponencial & 0,01 & 18,6 & 174 & 45,4 \\
\hline Mi (\%) & Gaussiano & 0,01 & 18,79 & 274 & 36,3
\end{tabular}

Legenda- Co: Efeito Pepita; Co + C: patamar; RSS: soma dos quadrados dos resíduos; Ds: densidade do solo; Mi: microporos.

Tabela 3 - Parâmetros de ajuste dos modelos anisotrópicos testados.

\begin{tabular}{l|l|l|l|l|l|l|c}
\hline Variável & Modelo & Co & Co + C & Alcance & Alcance & RSS & Azimute \\
\hline Ma (\%) & Esférico & $\underline{0}$ & $\underline{28,9}$ & $\underline{400}$ & $\underline{600}$ & $\underline{494}$ & \\
\hline Ma (\%) & Exponencial & 0 & 38 & 1630 & 1660 & 1371 & $45^{\circ}$ \\
\hline Ma (\%) & Gaussiano & 0 & 30 & 662 & 680 & 766 & \\
\hline Vtp (\%) & Esférico & $\underline{0}$ & $\underline{16}$ & $\underline{513}$ & $\underline{843}$ & $\underline{191}$ & \\
\hline Vtp (\%) & Exponencial & 0 & 18,81 & 1024 & 1024 & 297 & $290^{\circ}$ \\
\hline Vtp (\%) & Gaussiano & 0 & 17 & 590 & 866 & 243 & \\
\hline K0 (cm/h) & Esférico & $\underline{0}$ & $\underline{83}$ & $\underline{300}$ & $\underline{600}$ & $\underline{13589}$ & \\
\hline K0 (cm/h) & Exponencial & 0 & 83 & 50 & 400 & 13648 & \\
\hline K0 (cm/h) & Gaussiano & 0 & 83 & 50 & 500 & 13629 & $45^{\circ}$ \\
\hline
\end{tabular}

Legenda- Co: Efeito Pepita; Co + C: patamar; RSS: soma dos quadrados dos resíduos; K0: condutividade hidráulica saturada; Ma: macroporos; Vtp: volume total de poros. 
Destaca-se a maior anisotropia encontrada para o atributo K0, com alcance de 2:1 na direção de maior continuidade. $\mathrm{O}$ ajuste do modelo esférico para K0 também foi encontrado por outros autores como Amorim et al. (2011);
Furtunato et al. (2013); Scherpinski et al. (2010).

Como todos os atributos apresentaram dependência espacial, a espacialização via K.O. foi realizada para areia, argila, silte, Ds, Ma, Mi, Vtp e K0 através de seus respectivos

Tabela 4 - Estatística descritiva dos valores gerados pela K.O.

\begin{tabular}{l|r|r|r|r|r|r}
\hline \multicolumn{1}{c|}{ Atributos } & Máximo & Mínimo & Amplitude & \multicolumn{1}{c}{ Média } & Variância & CV (\%) \\
\hline Areia (\%) & 87,12 & 65,41 & 21,71 & 78,05 & 23,27 & 6,18 \\
\hline Argila (\%) & 25,38 & 10,01 & 15,38 & 16,25 & 7,97 & 17,37 \\
\hline Silte (\%) & 23,14 & 2,14 & 21,00 & 5,86 & 9,28 & 52,03 \\
\hline Ds (g/cm) & 1,80 & 1,41 & 0,39 & 1,61 & 0,004 & 3,96 \\
\hline Ma (\%) & 25,09 & 3,24 & 21,85 & 13,32 & 8,75 & 22,22 \\
\hline Mi (\%) & 29,93 & 13,56 & 16,37 & 23,41 & 6,10 & 10,55 \\
\hline Vtp (\%) & 42,61 & 25,42 & 17,19 & 36,63 & 5,58 & 6,45 \\
\hline K0 (cm/h) & 41,33 & 0,22 & 41,11 & 7,39 & 20,43 & 61,13 \\
\hline Leg
\end{tabular}

Legenda - CV: coeficiente de variação; Ds: densidade do solo; K0: condutividade hidráulica saturada; Ma: macroporosidade; Mi: microporosidade; Vtp: volume total de poros.

Tabela 5- Teste de Tukey aplicado a todos os atributos analisados.

\begin{tabular}{c|c|c|c|c|c|c|c|c}
\hline & Areia & Argila & Silte & Ds & Ma & Mi & Vtp & Ko \\
\hline $\mathbf{t}_{\text {calc }}$ & 0,13 & 0,13 & 0,77 & 0,53 & 0,71 & 0,36 & 0,71 & 0,75 \\
\hline $\mathbf{t}_{\text {tab }}$ & \multicolumn{7}{c}{ - }
\end{tabular}

Legenda - K0: condutividade hidráulica saturada; Ds: densidade do solo; Ma: macroporosidade; Mi: microporosidade; Vtp: volume total de poros; $\mathrm{t}_{\text {calc }}$ : $\mathrm{t}$ calculado; $\mathrm{t}_{\mathrm{tab}}$ : $\mathrm{t}$ tabelado bicaudal, grau de liberdade 2 e alfa de 0,05 .

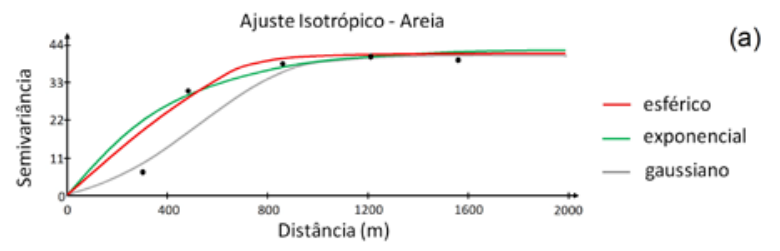

)

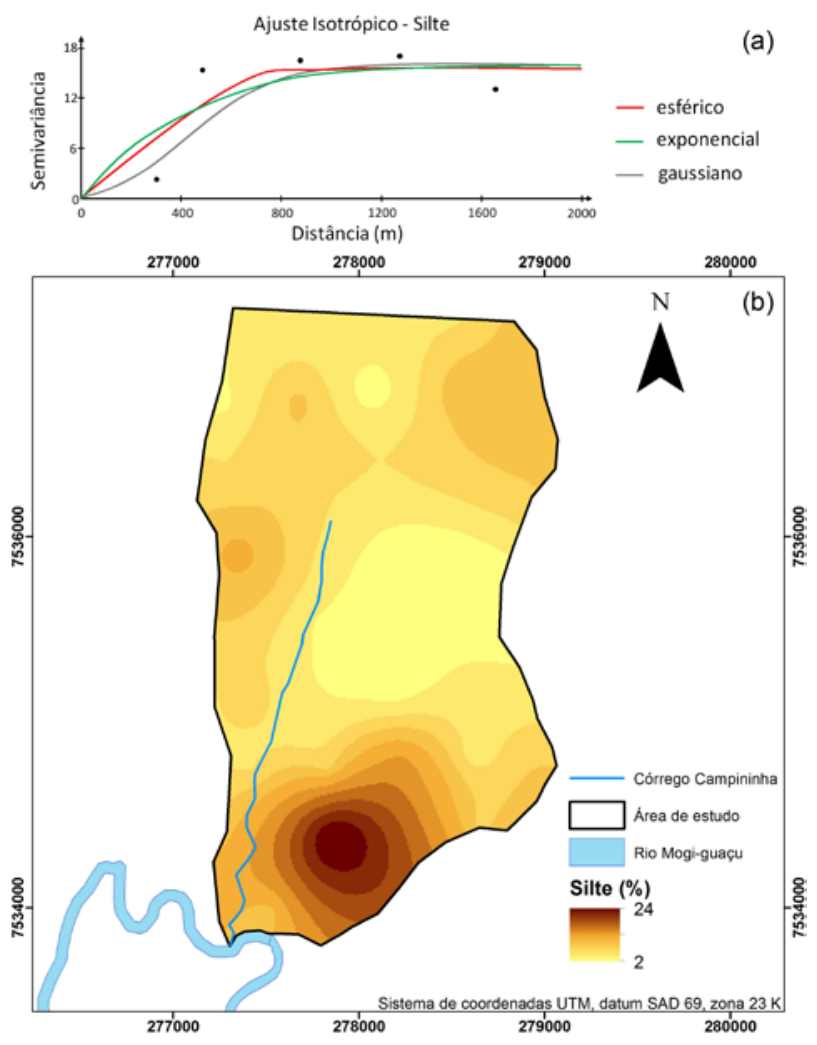

Figura 4 - a) Variograma isotrópico da fração silte.

Figura 3 - a) Variograma isotrópico da fração areia;

b) Mapa da distribuição dos atributos físico-hídricos do solo: fração areia.

b) Mapa da distribuição dos atributos físico-hídricos do solo: fração silte. 


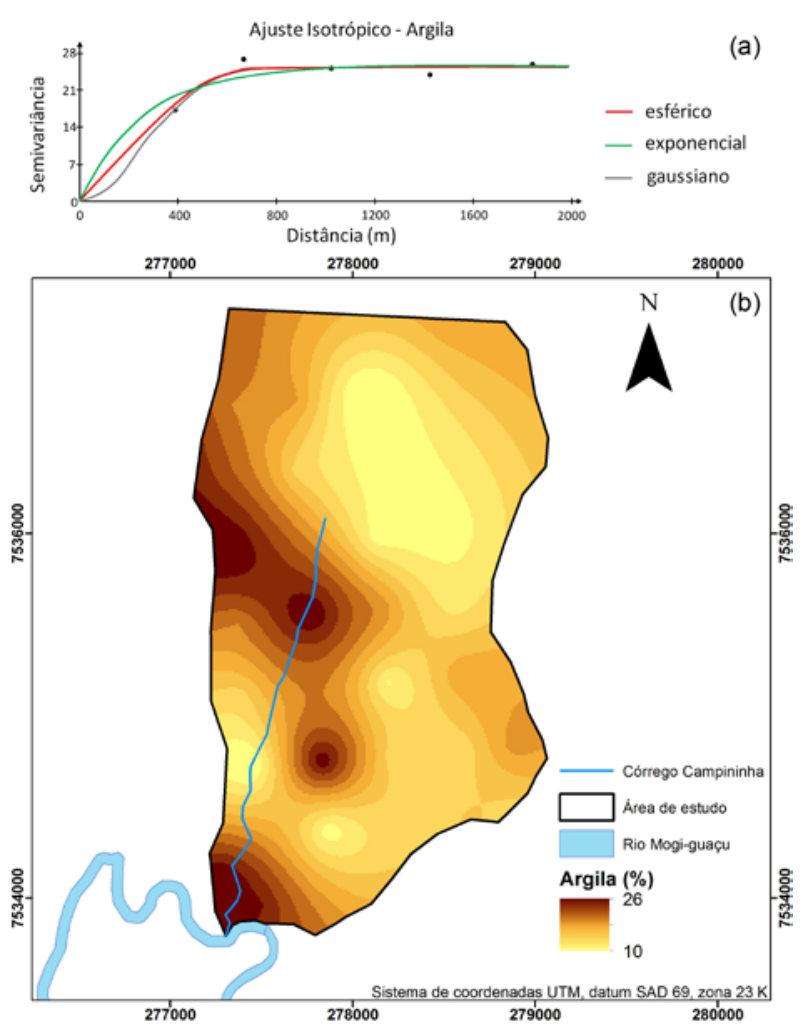

Figura 5 - a) Variograma isotrópico da fração argila. b) Mapa da distribuição dos atributos físico-hídricos do solo: fração argila.

modelos ajustados. Na análise da estatística descritiva apresentada na Tabela 4, pode-se observar que os parâmetros: máximo, mínimo, média e amplitude não apresentaram alterações entre as amostras e os modelos gerados pela K.O., entretanto, conforme o esperado, devido a formulação matemática da K.O., a variância e o CV diminuíram, contudo, ainda conservando boa parte da variabilidade original. $O$ teste de Tukey, que testou a hipótese de igualdade entre os valores amostrados e os valores krigados (H0), segue apresentado na Tabela 5. Para todos os atributos, com nível de confiança de 95\%, H0 foi aceita confirmando a consistência das estimativas da K.O. relatadas por autores como Furtunato et al. (2013), Kamimura et al. (2013), Lima et al. (2014), Oliver \& Webster (2014) e Parfitt et al. (2014).

Os modelos e mapas gerados são apresentados nas figuras 3 a 10. A interpolação dos dados através da K.O. permite gerar mapas de distribuição essenciais à análise do fluxo de água no perfil do solo capazes de identificar, consequentemente, áreas potenciais de recarga e áreas prioritárias de conservação, de modo a garantir a manutenção das condições favoráveis e manejar adequadamente as áreas menos favoráveis à infiltração de água.

A variabilidade espacial dos atributos físicos do solo constitui informação chave para garantir a conservação do mesmo, a qual afeta diretamente a preservação dos recursos hídricos tanto superficiais como subterrâneos.

Para a argila, a espacialização revelou maior teor nas partes mais baixas e próximas à rede de drenagem onde a K0 é menor (Figura 5) sendo relacionada, possivelmente, ao transporte diferenciado de sedimentos, pois as partículas mais finas como a argila são deslocadas com maior facilidade a distâncias maiores e alcançam as partes mais baixas do relevo (Gomes et al., 2007). Ao estudar a variabilidade da condutividade hidráulica dos solos de Goiás, Fiori et al. (2010) observaram resultados similares Para a argila, a espacialização revelou maior teor nas partes mais baixas e próximas à rede de drenagem onde a K0 é menor (Figura 5) sendo relacionada, possivelmente, ao transporte diferenciado de sedimentos, pois as partículas mais finas como a argila são deslocadas com maior facilidade a distâncias maiores e alcançam as partes mais baixas do relevo (Gomes et al., 2007). Ao estudar a variabilidade da condutividade hidráulica dos solos de Goiás, Fiori et al. (2010) observaram resultados similares quanto a interferência da argila na redução da condutividade hidráulica.

Em áreas de solo mais argiloso há uma redução na macroporosidade (Figura 6) responsável pelo movimento da água no perfil e um aumento da microporosidade (Figura 8) que favorece a retenção da água, decorrente do reduzido tamanho da partícula.

Em relação à Densidade do solo (Ds), contatou-se uma espacialização bastante homogênea na área de estudo, entretanto, podemos perceber uma ocorrência mais frequente de valores elevados nas proximidades da rede de drenagem, em áreas com valores relativamente baixos de K0 (Figura 7). O mesmo padrão foi encontrado de forma inversa para a macroporosidade, registrada com valores maiores onde a Ds é menor e valores menores onde a Ds é maior, conforme o esperado. As áreas a sudeste do levantamento apresentaram os maiores valores de K0 e também de Ma (Figura 6), confirmando a relação direta entre estes dois atributos, também relatado por Fiori et al. (2010). 

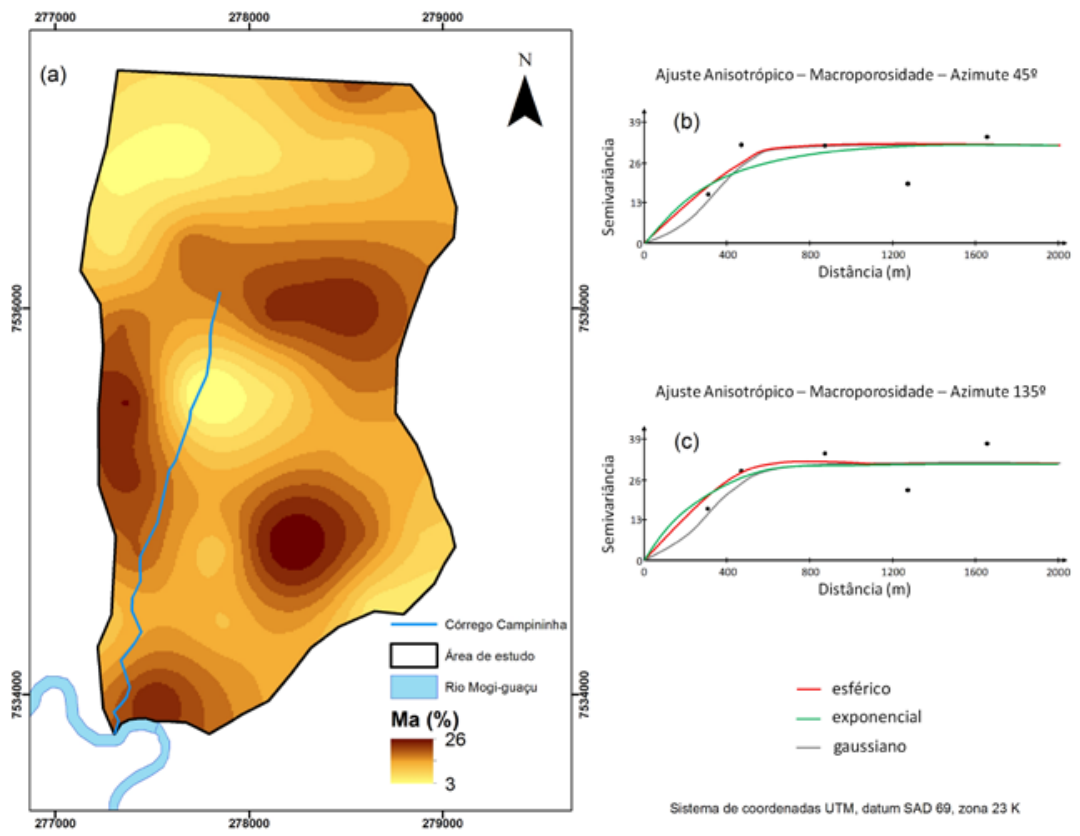

Figura 6 - a) Mapa da distribuição dos atributos físico-hídricos do solo: macroporosidade. b) Variograma isotrópico da macroporosidade $\left(45^{\circ}\right)$. c) Variograma isotrópico da macroporosidade (135).

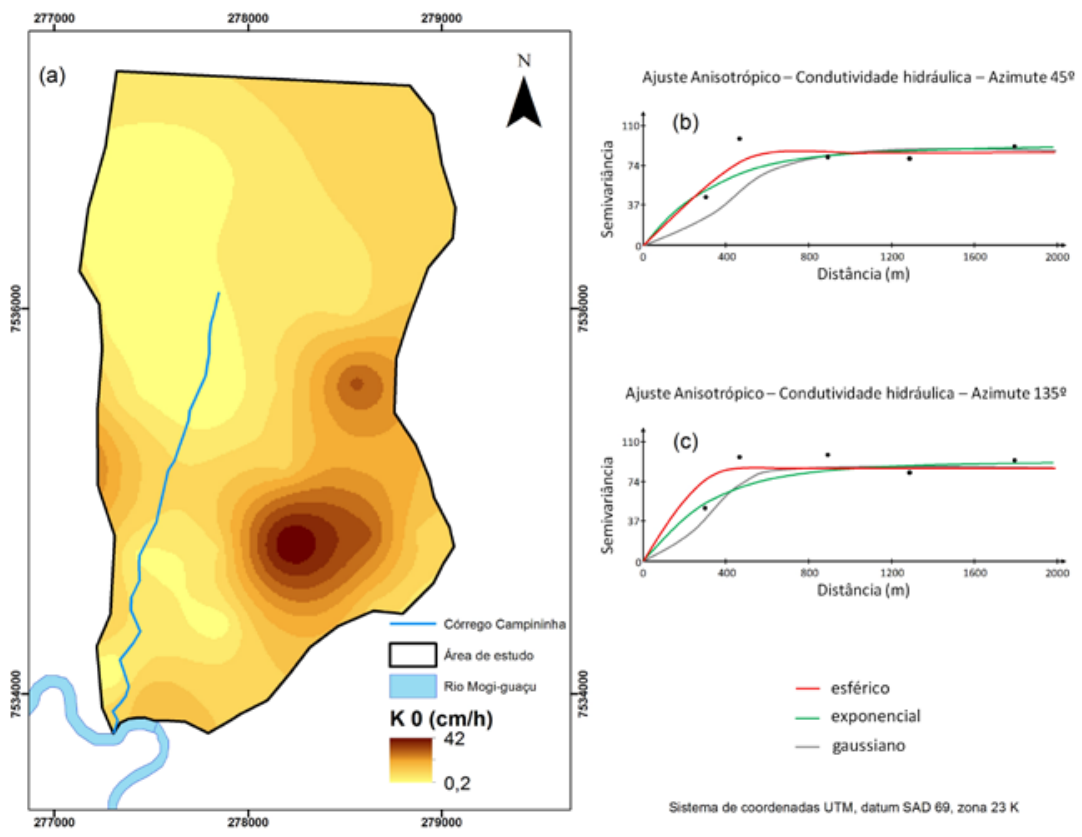

Figura 7 - a) Mapa da distribuição dos atributos físico-hídricos do solo: condutividade hidráulica. b) Variograma isotrópico da condutividade hidráulica $\left(45^{\circ}\right)$. c) Variograma isotrópico da condutividade hidráulica $\left(135^{\circ}\right)$.

Os menores valores de K0 foram observados, de maneira geral, próximos à rede de drenagem, indicando que o fluxo superficial tende a escoar pela rede e não conseguir boa taxa de infiltração. Assim, tais áreas são menos favoráveis à recarga de água, situação a qual caracteriza, considerando as características edáficas acima mencionadas e a topografia pouco movimentada (Figura 1), a maior propensão ao assoreamento nas áreas de drenagem e a importância da cobertura vegetal permanente como mecanismo de proteção dos canais fluviais. A preservação da vegetação exerce função primordial para a recarga de água, conforme verificado por Lima et al. (2013) ao estimar áreas com potencial de recarga e sub-bacia componente do Sistema Cantareira. Dessa forma, a vegetação nas áreas de menor potencial de recarga favorece a retenção hídrica na superfície e subsuperfície do solo e evita que a taxa de entrada subterrânea da água seja ainda menor, podendo reduzir a vazão do curso d’água. 


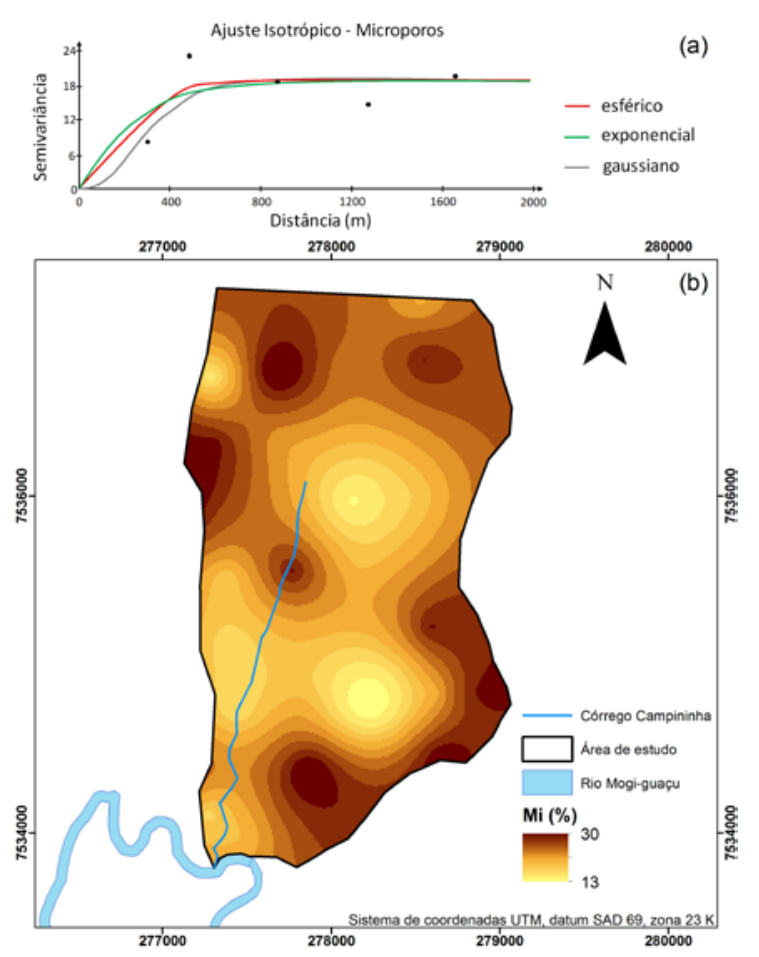

Figura 8 - a) Variograma isotrópico da microporosidade. b) Mapa da distribuição dos atributos físico-hídricos do solo: microporosidade.
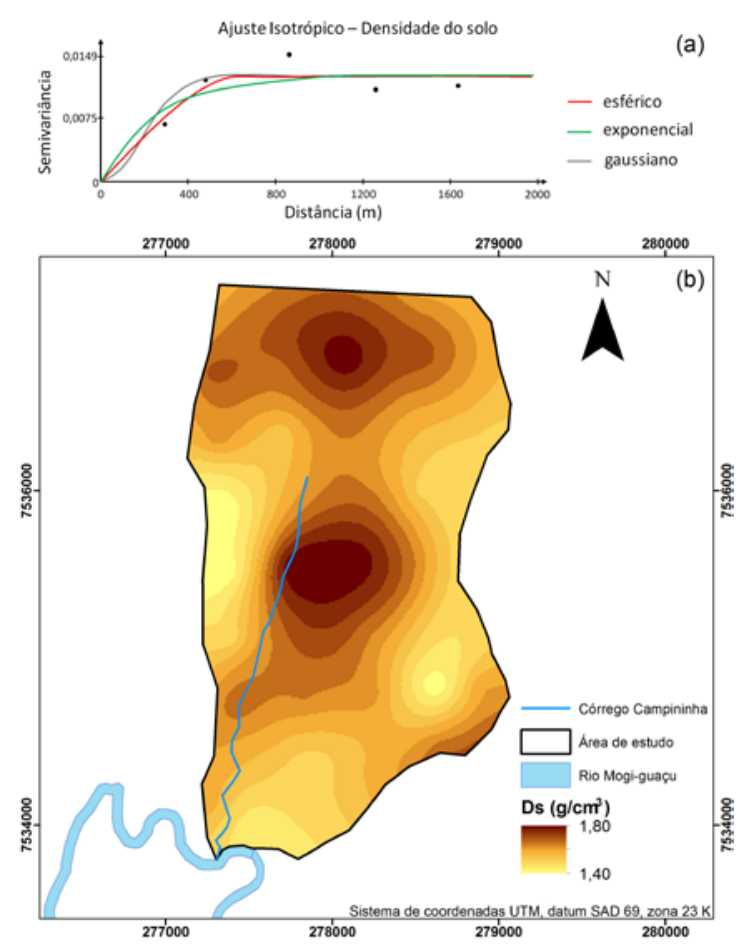

Figura 9 - a) Variograma isotrópico da densidade do solo. b) Mapa da distribuição dos atributos físicohídricos do solo: densidade do solo.

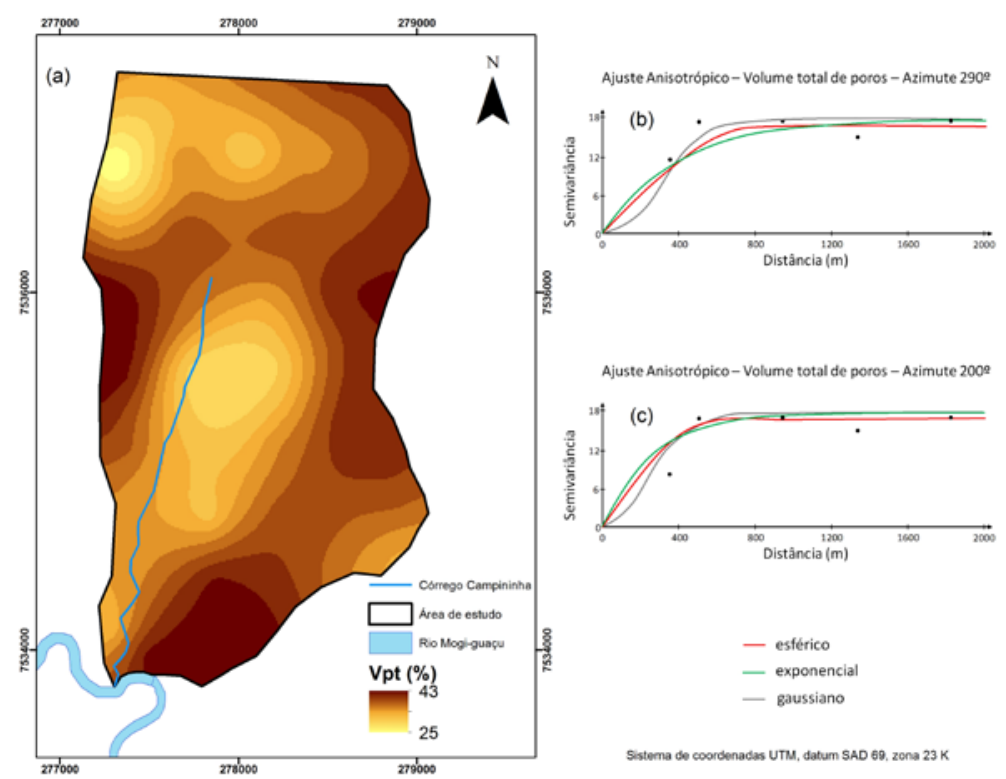

Figura 10 - a) Mapa da distribuição dos atributos físico-hídricos do solo: volume total de poros. b) Variograma isotrópico do volume total de poros $\left(290^{\circ}\right)$. c) Variograma isotrópico do volume total de poros $\left(200^{\circ}\right)$.

\section{CONCLUSÕES}

A melhor correlação encontrada entre todos os atributos estudados e a condutividade hidráulica foi 0,53 para a macroporosidade, confirmando a importância dos macroporos no transporte de água no perfil do solo.

A hipótese testada de dependência espacial para os atributos areia, silte, argila, condutividade hidráulica, densidade, macroporosidade, microporosidade e volume total de poros foi confirmada para todos.

Em relação à hipótese de anisotropia, a mesma só foi constatada para os atributos condutividade hidráulica, macroporosidade e volume total de poros, sendo os demais considerados isotrópicos na escala deste estudo.

Em vista da relação entre geração de fluxo e infiltração de água na área de planície aluvionar adjacente ao Rio Mogi Guaçu, alvo deste estudo, 
os atributos físico-hídricos do solo apresentaram características favoráveis à infiltração, refletidas na média elevada da condutividade hidráulica.
Tal condição é ainda favorecida, considerando a predominância da ocupação florestal e o relevo plano/ondulado da área.

\section{AGRADECIMENTOS}

À CAPES e ao CNPq pela concessão das bolsas de estudo aos autores deste trabalho; à Fundação de Amparo à Pesquisa do Estado de São Paulo (FAPESP) pelo financiamento do projeto ( $\mathrm{N}^{\circ}$ 2013/22729-2); e ao Instituto Florestal (IF-SP) pelo apoio logístico para condução do estudo.

\section{REFERÊNCIAS}

ALVARENGA, C.C.; MELLO, C.R. DE; MELLO, J.M. DE; VIOLA, M.R. Continuidade espacial da condutividade hidráulica saturada do solo na bacia hidrográfica do Alto Rio Grande, MG. Revista Brasileira de Ciência do Solo, v. 35, n. 5, p. $1745-1757,2011$.

ALVARENGA, C.C.; MELLO, C.R. DE; MELLO, J.M. DE; SILVA, A.M. DA; CURI, N. Índice de qualidade do solo associado à recarga de água subterrânea (IQSRA) na Bacia Hidrográfica do Alto Rio Grande, MG. Revista Brasileira de Ciência do Solo, v. 36, n. 5, p. 1608-1619, 2012.

AMORIM, D.D.; GONTIJO, I.; SANTOS, E.O. DE J.; NICOLE, L.R. Correlação espacial entre a condutividade hidráulica e atributos físicos do solo. Enciclopédia Biosfera, v. 7, n. 13, p. 263-265, 2011.

BATISTA, E.A. \& COUTO, H.T.Z. do. Influência de fatores físicos do solo sobre o desenvolvimento das espécies florestais mais importantes do cerrado da Reserva Biológica de Moji-Guaçu, SP. In: CONGRESSO NACIONAL SOBRE ESSÊNCIAS NATIVAS, 2, 1992. Resumos Expandidos... São Paulo: Instituto Florestal, 1992, p. 318-323.

BAVER, L.D.; GARDNER, W.H.; GARDNER, W.R. Soil physics. New York: J. Wiley, 498 p. 1972.

BLAKE, G.R. Particle Density. In: BLACK, C.A (Coordinator). Methods of Soil Analysis: Part 1-Physical and Mineralogical Properties, including Statistics of Measurement and Sampling. Madison, Wisconsin USA: American Society of Agronomy, Inc., p. 371-373. 1965.

BOUYOUCOS, G.H. A Recalibration of the hydrometer for making mechanical analysis of soils. Journal of Agronomy, Madison, v.43, n. 9, p. 434-438, 1951.

CARVALHO, M.P.; TAKEDA, E.Y.; FREDDI, O.S. Variabilidade espacial de atributos de um solo sob videira em Vitória Brasil (SP). Revista Brasileira de Ciência do Solo, v. 27, n. 4, 2003.

CERRI, C.E.P.; BERNOUX, M.; CHAPLOT, V.; VOLKOFF, B.; VICTORIA, R.L.; MELILLO, J.M.; PAUSTIAN, K.; CERRI, C.C. Assessment of soil property spatial variation in an Amazon pasture: Basis for selecting an agronomic experimental area. Geoderma, v. 123, n. 1-2, p. 51-68, 2004.

CHANG H.K.; TEIXEIRA, A.J.; VIDAL, A.C. Aspectos hidrogeológicos e hidroquímicos das regiões dos municípios de Mogi Mirim, Mogi Guaçu e Itapira no Estado de São Paulo. Geociências, v. 22, nº especial, p. 63-73, 2003.

CHILÈS, J.P. \& DELFINER, P. Geostatistics: Modeling Spatial Uncertainty. New York: John Wiley \& Sons, 695p. 2012.

DANIELSON, R.E. \& SUTHERLAND, P.L. Porosity. In: KLUTE A. (Coordinator) Methods of Soil Analysis: Part 1-Physical and Mineralogical Methods. Madison, Wisconsin USA: American Society of Agronomy, Inc. \& Soil Science Society of America, Inc., p.443-462. 1986.

EMBRAPA. Sistema brasileiro de classificação de solos. Rio de Janeiro: Empresa Brasileira de Pesquisa Agropecuária, 306 p. 2006.

FIORI, J.P.O.; CAMPOS, J.E.G.; ALMEIDA, L. Variabilidade da condutividade hidráulica das principais classes de solos do Estado de Goiás. Geociências, v. 29, n. 2, p. 229-235, 2010.

FREIRE, O. Solos das regiões tropicais. Botucatu: Fundação de Estudos e Pesquisas Agrícolas e Florestais, 271 p. 2006.
FURTUNATO, O.M.; MONTENEGRO, S.M.G.L.; ANTONINO, A.C.D.; OLIVEIRA, L.M.M. DE; SOUZA, E.S. DE; MOURA, A.E.S.S. DE. Variabilidade Espacial de Atributos Físico-hídricos de Solos em uma Bacia Experimental no Estado de Pernambuco. Revista Brasileira de Recursos Hídricos, v. 18, n. 2, p. 135-147, 2013.

GOMES, N.M.; FARIA, M. A. DE; SILVA, A.M.; MELLO, C.R. DE; VIOLA, M.R. Variabilidade espacial de atributos físicos do solo associados ao uso e ocupação da paisagem. Revista Brasileira de Engenharia Agrícola e Ambiental, v. 11, n. 4, p. 427-435, 2007.

GROHMANN, F. Distribuição e tamanho de poros em três tipos de solos do estado de São Paulo. Bragantia - Boletim Técnico do Instituto Agronômico do Estado São Paulo, v. 19, n. 21, p. 319-328, 1960.

INSTITUTO DE PESQUISAS TECNOLÓGICAS DO ESTADO DE SÃO PAULO (IPT). Mapa Geológico do Estado de São Paulo. São Paulo: IPT, 1981.

KAMIMURA, K.M.; DOS SANTOS, G.R.; OLIVEIRA, M.S. DE; DIAS JUNIOR, M.D.S.; GUIMARÃES, P.T.G. Variabilidade espacial de atributos físicos de um latossolo vermelho-amarelo, sob lavoura cafeeira. Revista Brasileira de Ciência do Solo, v. 37, n. 4, p. 877-888, 2013.

KLUTE, A. Laboratory measurement of hydraulic conductivity of saturated soil. In: BLACK CA (Coordinator). Methods of Soil Analysis: Part 1-Physical and Mineralogical Properties, including Statistics of Measurement and Sampling. Madison, Wisconsin USA: American Society of Agronomy, Inc., p. 210-221, 1965.

KUTÍLEK, M. \& NIELSEN, D.R. Soil hydrology. Reiskirchen, Germany: Catena Verlag GMBH, 370 p., 1994.

LANDIM, P.M.B. \& STURARO, J.R. Krigagem indicativa aplicada à elaboração de mapas probabilísticos de riscos. Rio Claro - SP. DGA, IGCE-UNESP/Rio Claro, Lab. Geomatemática, Texto Didático 06, 19 p. 2002. Disponível em: www.rc.unesp.br/igce/aplicada/DIDATICOS/LANDIM/ kindicativa.pdf. Acesso em: 09/09/2015.

LIMA, G.C.; SILVA, M.L.N.; CURI, N.; SILVA, M.A. DA; OLIVEIRA, A.H.; AVANZI, J.C.; FREITAS, D.A.F. de. Estimativa do potencial de recarga na Sub-bacia das Posses, Extrema (MG), em função dos atributos fisiográficos, pedológicos e topográficos. Geociências, v. 32, n. 1, p. 5162, 2013.

LIMA, G.C.; SILVA, M.L.N.; OLIVEIRA, M.S. DE; CURI, N., SILVA, M.A. DA; OLIVEIRA, A.H. Variabilidade de atributos do solo sob pastagens e mata atlântica na escala de microbacia hidrográfica. Revista Brasileira de Engenharia Agrícola e Ambiental, v. 18, n. 5, p. 517-526, 2014.

MATHERON, G. Les Variables Régionalisées et leur estimation: Une Application de la Théorie des Fonctions Aléatoires aux Sciences de la Nature. Paris: Masson, 305 p., 1965.

MELLO, C.R. de \& CURI, N. Hydropedology. Ciência \& Agrotecnologia, v. 36, n. 2, p. 137-146, 2012.

MENEZES, M.D.; JUNQUEIRA JÚNIOR, J.A. MELLO, C.R.DE; SILVA, A.M. DA; CURI, N.; MARQUES, J.J. Dinâmica hidrológica de duas nascentes, associada ao uso do solo, características pedológicas e atributos físico-hídricos na 
sub-bacia hidrográfica do Ribeirão Lavrinha, Serra da Mantiqueira, MG. Scientia Forestalis, v. 82, n. 37, p. 175184, 2009.

OLIVER, M.A. \& WEBSTER, R. A tutorial guide to geostatistics: Computing and modelling variograms and kriging. Catena, v. 113, n. 1, p. 56-69, 2014.

PARFITT, J.M.B.; TIMM, L.C.; REICHARDT, K.; PAULETTO, E.A. Impacts of Land Leveling on Lowland Soil Physical Properties. Revista Brasileira de Ciência do Solo, v. 38, n. 1, p. 315-326, 2014.

PETRI, S. \& FÚLFARO, V.J. Geologia do BrasilFanerozóico. QUEIROZ, T.A. (Coordenador). Editora da USP: São Paulo. 1983. 631 p. 1983.

RIBEIRO, K.D.; MENEZES, S.M.; MESQUITA, M.G.B.F.; SAMPAIO, F.M.T. Propriedades físicas do solo, influenciadas pela distribuição de poros, de seis classes de solos da região de Lavras-MG. Ciência \& Agrotecnologia, v. 31, n. 4, p. 1167-1175, 2007.

ROBINSON, T.P. \& METTERNICHT, G. Testing the performance of spatial interpolation techniques for mapping soil properties. Computers and Electronics in Agriculture, v. 50, n. 2, p. 97-108, 2006.

SANTOS, D. DOS; SOUZA, E.G. DE; NÓBREGA, L.H.P.; BAZZI, C.L.; GONÇALVES JÚNIOR, A.C. Variabilidade espacial de atributos físicos de um Latossolo Vermelho após cultivo de soja. Revista Brasileira de Engenharia Agrícola e Ambiental, v. 16, n. 8, p. 843-848, 2012a.

SANTOS, K.S.; MONTENEGRO, A.A.A.; ALMEIDA, B.G. DE; MONTENEGRO, S.M.G.L.; ANDRADE, T.D.S.; FONTES JÚNIOR, R.V.D.P. Variabilidade espacial de atributos físicos em solos de vale aluvial no semiárido de Pernambuco. Revista Brasileira de Engenharia Agrícola e Ambiental, v. 16, n. 8, p. 828, 2012b.
SANTOS, R.D.; LEMOS, R.C.; SANTOS, H.G.; KER, J.C.; ANJOS, L.H.C. Manual de descrição e coleta de solo no campo. Sociedade Brasileira de Ciência do Solo: Viçosa. 2005. 100 p.

SCHERPINSKI, C.; URIBE-OPAZO, M.A.; VILAS BOAS, M.A.; SAMPAIO, S.C.; JOHANN, J.A. Variabilidade espacial da condutividade hidráulica e da infiltração da água no solo. Acta Scientiarum Agronomy, v. 32, n. 1, p. 7-13, 2010.

SILVA, A.F. da; PEREIRA, M.J.; ZIMBACK, C.R.L.; LANDIM, P.M.B.; SOARES, A. Simulação sequencial de atributos diagnósticos do solo. Revista Brasileira de Engenharia Agícola e Ambiental, v. 19, n. 1, p. 418-425, 2015.

SPAROVEK, G.; VAN LIER, Q.D.J.; DOURADO NETO, D. Short Communication Computer assisted Koeppen climate classification: a case study for Brazil. International Journal of Climatology, v. 27, p. 257-266, 2007.

TEIXEIRA, W; TOLEDO, M.C.M. DE; FAIRCHILD, T.R.; TAIOLI, F. Decifrando a terra. 2. ed. São Paulo: Oficina de Textos, 558 p., 2003.

WARRICK, A.W. \& NIELSEN, D.R. Spatial variability of soil physical properties in the field. In: HILLEL, D. (Coordinator) Applications of soil physics, p. 319-344, 1980.

Manuscrito recebido em 18 de fevereiro de 2016 Revisado e aceito em 9 de novembro de 2016 